\title{
Low-Cost GPS-Based Volcano Deformation Monitoring at Mt. Papandayan, Indonesia
}

\author{
Volker Janssen, Craig Roberts, Chris Rizos \\ School of Surveying \& Spatial Information Systems \\ The University of New South Wales \\ Sydney NSW 2052, Australia \\ Hasanuddin Z. Abidin \\ Department of Geodetic Engineering \\ Institute of Technology Bandung \\ Bandung, Indonesia
}

\begin{abstract}
The Global Positioning System (GPS) can be utilised to detect ground deformations of the surface of a volcano. Ground deformation monitoring is considered one of the most effective tools for investigating the behaviour of active volcanoes. The decreasing cost of GPS hardware, together with the increased reliability of the technology, facilitates such demanding applications. GPS ground deformation measurements can be continuous, automatic, conducted in all weather conditions and, provide threedimensional positioning results. Higher computing power also means that the complex mathematics required to process GPS baselines can be easily handled in near real time.

During the past few years a methodology has been developed for processing data collected by GPS networks consisting of a mixed set of single-frequency and dual-frequency receivers. The strategy is to deploy a few permanent, 'fiducial' GPS stations with dual-frequency, geodetic-grade receivers surrounding an 'inner' network of low-cost, single-frequency GPS receivers. Such a configuration offers considerable flexibility and cost savings for geodynamic applications such as volcano deformation monitoring, which require a dense spatial coverage of GPS stations, and where it is not possible to establish permanent GPS networks using only expensive dual-frequency instrumentation.
\end{abstract}

This configuration has recently been tested at the Mt. Papandayan volcano in West Java, Indonesia. The two-stage network design consists of an inner network of four single-frequency Canadian Marconi (CM) GPS receivers surrounded by three dual-frequency Leica CRS1000 GPS receivers. The inner network logged and transmitted GPS data from the 'slave' stations located on the volcano, to a base station. The combined processing of the $\mathrm{CM}$ and Leica receiver data was performed offline so as to investigate the performance of such a mixed-mode system. The basis of the processing methodology is to separate the dual-frequency, 'fiducial' station data processing from the baseline processing involving the singlefrequency receivers on the volcano. The data processing for the former was carried out using a modified version of the Bernese software, to generate a file of 'corrections' (analogous to Wide Area DGPS correction models for the distance dependent biases -- primarily due to atmospheric refraction). These 'corrections' were then applied to the double-differenced phase observations from the inner receivers to improve the baseline accuracies. A description of the field testing (and its challenges) during FebruaryMarch 2000, together with a discussion of some of the results are presented.

\section{KEYWORDS}

GPS; deformation monitoring; geodesy; ionosphere; low-cost 


\section{INTRODUCTION}

Ground deformation monitoring techniques for volcanic environments have developed from precise spirit levelling to electronic distance measuring (EDM) techniques, and now to campaign-style GPS surveys.

Perhaps the first documented ground deformation associated with a volcanic event was the work reported by Omori (1914). His investigations indicated vertical ground displacements on the Mt. Usu volcano in Japan of up to 2 metres when conducting precise levelling surveys before and after the eruption of 1910. A 100-metre upheaval of the ground surface was also recorded close to the crater at the time of eruption. Suganda (1993) reports a $2 \mathrm{~m}$ change of horizontal distance between points spanning the crater of Mt Merapi in Indonesia from four campaigns of EDM measurements conducted between 1988 - 1992.

In recent years, interferometric synthetic aperture radar (INSAR) techniques have increasingly been used to map the topography of volcanoes and detect ground deformation. Using ERS1 SAR images taken between 1992 and 1993, Briole et al (1997) detected a deflation "moderate in size and amplitude" associated with the 1986-87 and 1989 lava flows on Mt Etna, Italy. Around the vent of New Trident volcano in Alaska, a $7-9 \mathrm{~cm}$ uplift was observed in a 2-year period by Lu et al (1997). However, these techniques rely on the repeat period of the satellite track (35 days in the case of ERS1/2), which also influences the coherence of the images.

Ground deformation caused by magma intrusion and lava discharge was detected and reported in Nishi et al (1999) after a series of GPS campaigns were conducted over 6 years. In addition, the Institute of Technology Bandung (ITB) conducts quarterly campaigns on Gunung Guntur and Gunung Papandayan in West Java, Indonesia (Abidin et al, 1998). Local GPS campaigns are still used to monitor dome growth in conjunction with EDM distance measurements on Mt Etna, Italy (Nunnari \& Puglisi 1994).

All of these techniques, however, are campaign-style surveys, ie short measurement surveys separated by long time periods that give no indication of ground movement between the campaigns. The setting up of a continuous GPS infrastructure is cumbersome, but provides continuous measurements of the movement of volcano monitoring points. These measurements can provide both position and height to centimetre-level accuracy unlike levelling, which only produces height, and EDM, which only measures distance. Additionally there is no requirement for intervisibility of stations within a GPS network, measurements can be made in all weather, 24 hours per day and over relatively long distances. GPS is well suited to operate automatically in a remote environment powered by batteries and solar panels, with the logged data being transmitted to an office via a radio link.

One of the first continuous GPS networks was established in March 1988 on the Izu Peninsula in central Japan to support earthquake prediction research. Daily observations of this network led to the first GPS measurements of surface deformation as they occurred. Shimada et al (1990) reported that, "We have, for the first time, used GPS fixed-point measurements to follow the evolution with time of the crustal movements; such measurements provide a continuous uninterrupted record of deformation."

The aim of this project was to demonstrate that a continuous low-cost GPS monitoring system is an appropriate method for ground deformation monitoring to aid volcano studies. The objective is to measure centimetre accuracy, three-dimensional coordinates of stationary points. Re-measuring these same points on a continuous basis (many times a day) will produce a time series of coordinates which can be further analysed in order to extract possible deformational signals of the volcano. The system design requirements dictate the use of low-cost components so that a station setup will cost less than US $\$ 3000$ (including monuments). Meertens (1999) reports on a similar low-cost approach at the Long Valley Caldera, USA and Mt Popocatepetl, Mexico.

A single-frequency, carrier phase-tracking system is appropriate for small-scale continuous GPS networks if the baseline lengths are no longer than 10 kilometres. This 'rule-of-thumb' implies that the differential ionospheric and tropospheric delays between the two receivers is essentially zero, and therefore does not impact on the baseline result. Orbit bias over such short distances can also be ignored (Rizos, 1997). Presently, however, with the current solar sunspot cycle maximum, ionospheric disturbances have indeed 
corrupted baseline measurements over distances less than $10 \mathrm{~km}$ on Mt. Papandayan, adversely affecting baseline repeatability.

In order to ensure cm-level accuracy for baseline lengths (particularly those exceeding 10km), the singlefrequency network has been augmented by the addition of an outer 'fiducial' network of dual-frequency GPS receivers. This dual-frequency network surrounding the deformation zone of the volcano is used to generate 'correction terms' in order to improve the accuracy of the single-frequency baselines.

This paper describes the design of the inner and fiducial networks, and the ionospheric correction model proposed for this mixed-mode system. The problems encountered with its installation on Mt. Papandayan (Fig. 1) and the extraordinary effects of the ionosphere on baseline repeatability and the 'correction terms' experienced during this period will be discussed.

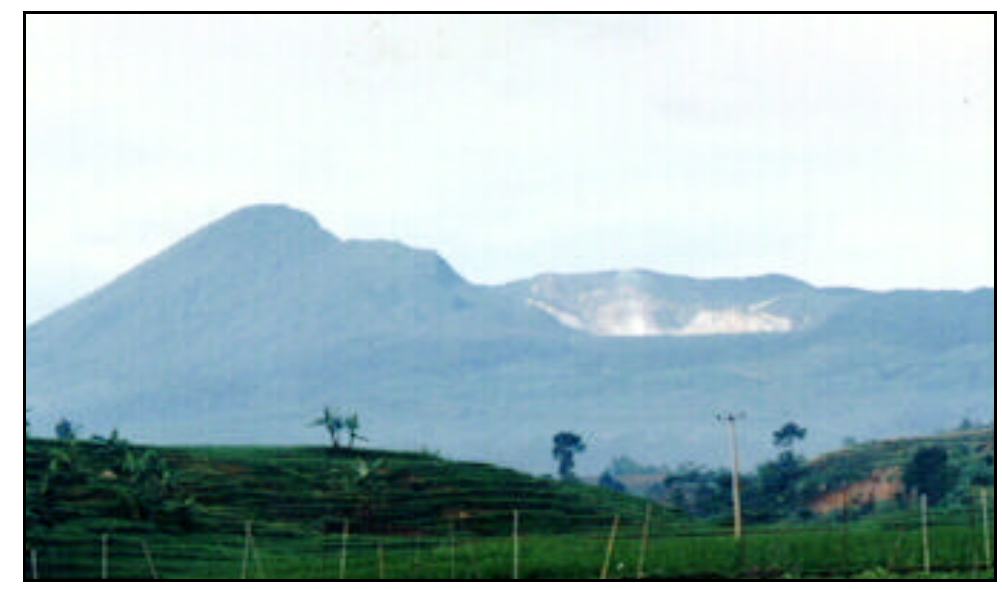

Fig. 1: Mt. Papandayan volcano in West Java, Indonesia

\section{INNER NETWORK DESIGN AND EQUIPMENT}

The University of New South Wales (UNSW) has coordinated the design and assembly of the deformation monitoring system. Rizos et al (2000) describe the four-station inner network of low-cost, single-frequency GPS receivers. The network array consists of one base station situated at the Papandayan observatory and three 'slave' stations located approximately $8 \mathrm{~km}$ away in the zone of deformation around the crater of the volcano. Each station comprises five components: (1) GPS/PC module, (2) radio modem sub-system, (3) monument, (4) GPS antenna, and (5) power supply.

Custom-built GPS/PC modules integrate a single-frequency, Canadian Marconi GPS board with an 8086 PC board which controls data decoding, file management and communications. GPS data is logged hourly at all stations. The base station sequentially polls the three slave stations and downloads their binary data files via a VHF radio link. This data is then automatically converted to the Receiver INdependent EXchange (RINEX) format and stored on a hard disk at the base station. Therefore 24 one-hour files are generated daily for each station.

Berntsen 3D monuments were emplaced and concreted in position at suitable locations. Issues such as skyview, site stability, line-of-sight for radio communications and avoidance of corrosive gases were important considerations for the location of the monuments. Additionally, the advice of experts from the Vulcanological Survey of Indonesia (VSI) was sought to locate the stations in order to most likely detect any deformations of the volcano. A $1.5 \mathrm{~m}$ fibreglass pole is used to mount a MicroPulse L1 lightweight survey GPS antenna at all stations.

The slave stations are powered by 12 VDC lead acid batteries charged continuously by solar panels. The base station is powered by AC power backed up by an uninterrupted power supply (UPS) to guard against 
spikes, surges or blackouts. The UPS has been additionally modified with larger backup batteries and an extra battery charger to provide continuous operation during extended blackouts (not uncommon in rural Indonesia). Figure 2 shows the main components of the slave station equipment: GPS/PC module, radio modem, single-frequency antenna and cables.

All software to operate this inner network was developed at UNSW to ensure maximum design flexibility. While the software is capable of automatic baseline processing, the data quality precludes this at present and all baseline results referred to in this paper have been post-processed.

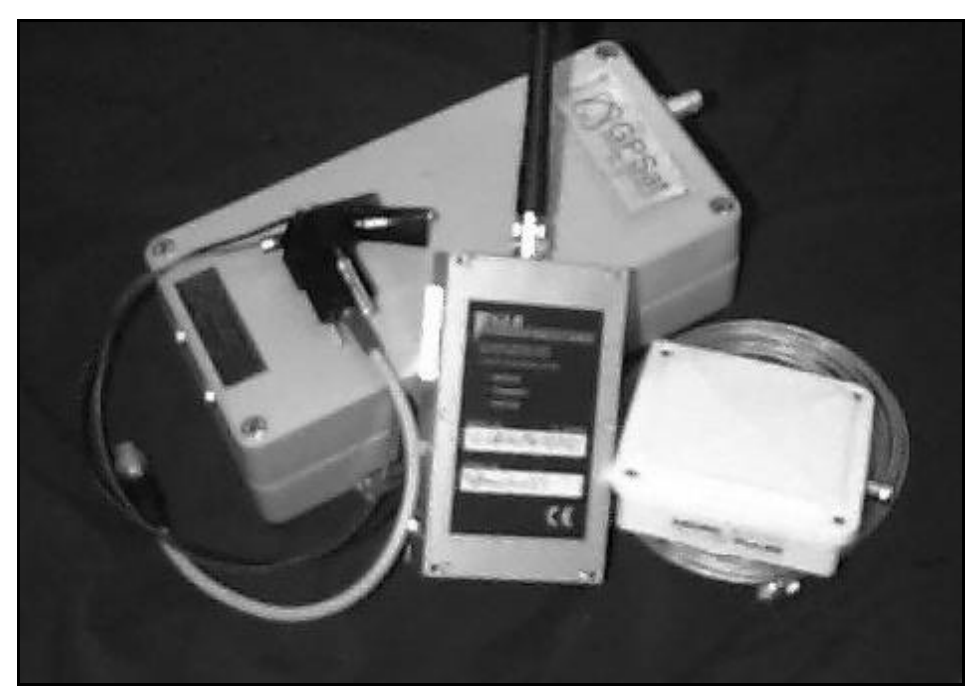

Fig. 2: Single-frequency GPS station equipment in the UNSW system

\section{FIDUCIAL NETWORK DESIGN AND EQUIPMENT}

A fiducial network of three dual-frequency GPS receivers surrounding the deformation zone of the volcano was used to generate empirical 'correction terms' (Rizos et al, 1998; Rizos et al, 1999). A technique known to geodesists as 'double differencing' is employed to eliminate certain errors (predominantly satellite and receiver clock errors) and thereby attain accuracies suitable for GPS surveying. These doubledifferenced corrections are then applied to the data from the single-frequency baselines in the inner network on the volcano to account for residual atmospheric biases.

As described in Han (1997), the fiducial network should ideally surround the inner single-frequency network. Figure 3 shows the ideal network configuration, where the triangles denote fiducial stations while the dots indicate the single-frequency sites. 




Fig. 3: Ideal mixed-mode network configuration for deformation monitoring

However, this ideal configuration could not be realised due to the need for continuous AC power and secure locations for the stations in a rather remote part of West Java, Indonesia. The fiducial network comprises three GPS stations located in Bandung, Galunggung and Pameungpeuk, forming a $72 \mathrm{~km}-60 \mathrm{~km}-$ $85 \mathrm{~km}$ triangle enclosing the deformation zone of the volcano. This configuration leaves the inner network close to the baseline Bandung-Pameungpeuk, but still well inside the triangle (Fig. 4). The equipment used was: Leica CRS1000 dual-frequency GPS receivers equipped with multipath resistant choke ring antennas, a 120 Ah battery and a battery charger. The battery charger and battery were used to guard against power outages, as the AC power supply is not always reliable in Indonesia. 


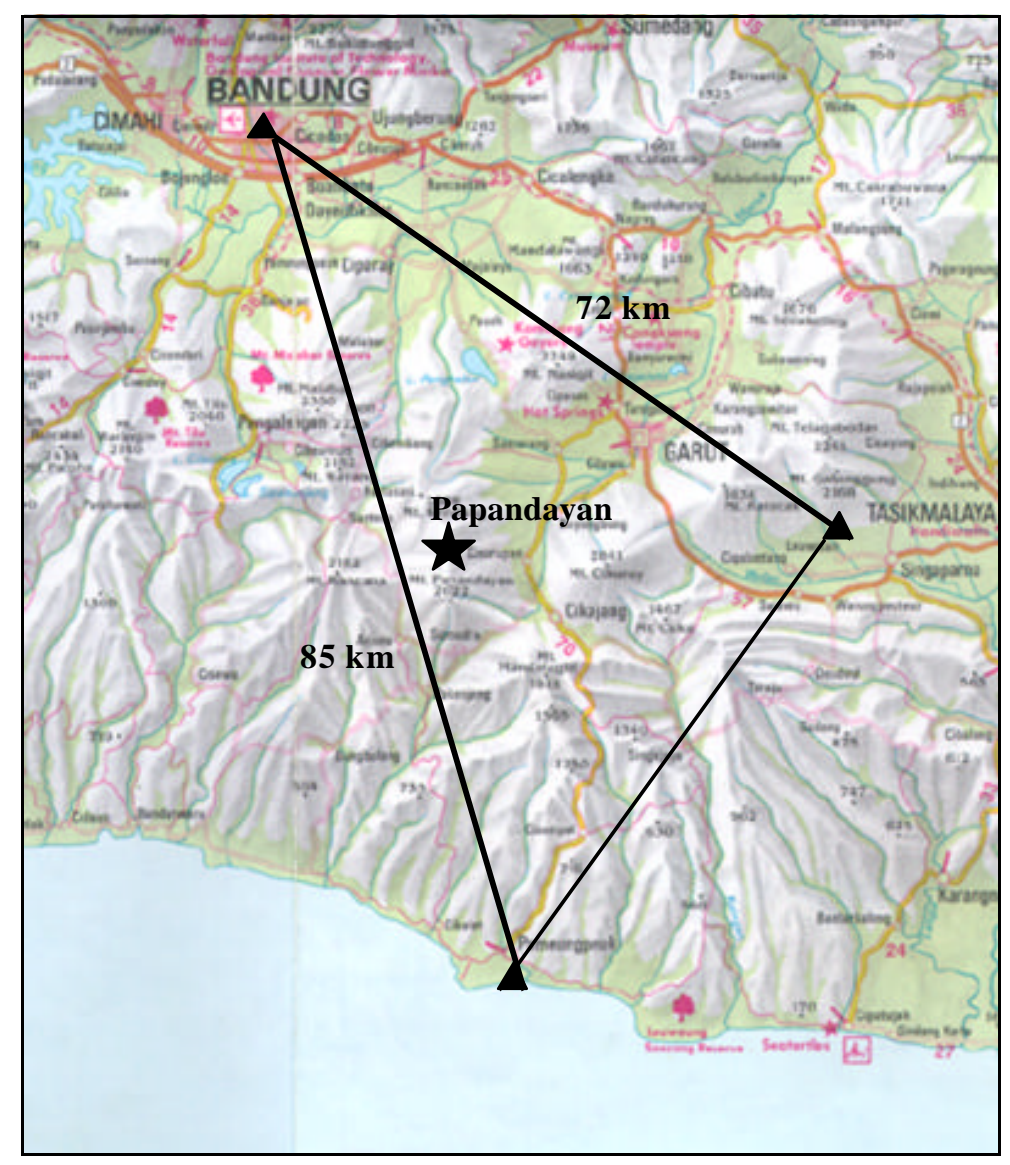

Fig. 4: GPS network around the Mt. Papandayan volcano, West Java, Indonesia

\section{IONOSPHERIC CORRECTIONS}

The ionospheric layer is part of the Earth's atmosphere and located approximately $50 \mathrm{~km}-1000 \mathrm{~km}$ above the surface. It has a major effect on GPS signals travelling from the satellite (around 20,200km above the Earth's surface) to the receiver.

The ionosphere is most active in a band extending up to approximately $20^{\circ}$ on either side of the magnetic equator. This is also one of the two regions where small-scale ionospheric disturbances (scintillations) mainly occur, the other being the high-latitude region close to the poles. Scintillations are short-term signal variations in amplitude and phase. In the equatorial region scintillations occur between approximately one hour after sunset until midnight (Klobuchar, 1996) and should have disappeared by 3am local time (IPS Radio \& Space Services, 2000). The occurrence of scintillations also varies seasonally. Between April and August they are less severe in the American, African and Indian longitude regions, but are at a maximum in the Pacific region, while the situation is reversed from September to March (Seeber, 1993). In midlatitudes, scintillations are rarely experienced, but Medium-Scale Travelling Ionospheric Disturbances (MSTIDs) occur frequently, mainly during daytime in the winter months, during periods of high sunspot cycle activity, with a maximum around local noon (Wanninger, 1999).

While dual-frequency GPS receivers can account for the ionospheric delay effect directly by the appropriate linear combination of measurements from both frequencies, single-frequency receivers cannot. Around the Mt. Papandayan volcano, a fiducial network of three dual-frequency receivers surrounding the deformation zone is used to generate 'correction terms', which can then be applied to the single-frequency observations to try to account for these effects. 
A linear combination model has been proposed by Han \& Rizos (1996) and Han (1997), which can account for orbit bias and ionospheric delay, as well as mitigate tropospheric delay, multipath and measurement noise across the network. Data from the fiducial GPS reference station network can be used to derive empirical corrections to the double-differenced carrier phase data formed between the stations of the inner network. The procedure is described in Chen et al (1999) and summarised below.

The double-differenced observable can be written as:

$$
\nabla \Delta \phi=\nabla \Delta \rho+\nabla \Delta d \rho+\lambda \cdot \nabla \Delta N-\nabla \Delta d_{i o n}+\nabla \Delta d_{\text {trop }}+\nabla \Delta d_{m p}^{\varphi}+\varepsilon_{\nabla \Delta \phi}
$$

where $\nabla \Delta=$ double-difference operator

$\phi=$ carrier phase observation in units of metres

$\rho=$ vector between receiver station and satellite

$\mathrm{d} \rho=$ effect of ephemeris errors

$\lambda=$ wavelength of the carrier phase

$\mathrm{N}=$ integer ambiguity for a particular satellite-receiver pair

$\mathrm{d}_{\text {ion }}, \mathrm{d}_{\text {trop }}, \mathrm{d}_{\text {mp }}^{\varphi}=$ ionospheric delay, tropospheric delay, multipath effect

$\varepsilon_{\nabla \Delta \phi}=$ carrier phase observation noise for a particular one-way observation

Assuming the number of GPS reference stations is three, the above equation can also be written in the form of a linear combination (Han, 1997):

$$
\nabla \Delta \phi_{u, 3}-\left[\alpha_{1} \cdot V_{1,3}+\alpha_{2} \cdot V_{2,3}\right]=\nabla \Delta \rho_{u, 3}+\lambda \cdot \nabla \Delta N_{u, 3}+\varepsilon_{\sum_{i=1}^{3} \alpha_{i} \cdot \nabla \Delta \phi_{i}}
$$

The parameters $\alpha_{I}$ can be determined based on the conditions given in Han \& Rizos (1996) and Wu (1994):

$\sum_{i=1}^{3} \alpha_{i}=1, \sum_{i=1}^{3} \alpha_{i} \cdot\left(\vec{X}^{s}-\vec{X}_{i}\right)=0$ and $\sum_{i=1}^{3} \alpha_{i}^{2}=\min$

where $X^{s}=$ satellite position vector and $X_{i}=$ receiver station position vector.

The residual vectors are formed from the double-differenced observations between reference stations $1 \& 3$ and $2 \& 3$ :

$$
\begin{aligned}
& V_{1,3}=\nabla \Delta \phi_{1,3}-\nabla \Delta N_{1,3}-\nabla \Delta \rho_{1,3} \\
& V_{2,3}=\nabla \Delta \phi_{2,3}-\nabla \Delta N_{2,3}-\nabla \Delta \rho_{2,3}
\end{aligned}
$$

The correction term $\left[\alpha_{1} \cdot V_{1,3}+\alpha_{2} \cdot V_{2,3}\right]$ can now be determined, and the linear combination between two stations $\mathrm{j}$ and $\mathrm{k}$ of the inner network (base and slave station on the volcano) can be written as:

$$
\nabla \Delta \phi_{k, j}-\left[\alpha_{1}^{k, j} \cdot V_{1,3}+\alpha_{2}^{k, j} \cdot V_{2,3}\right]=\nabla \Delta \rho_{k, j}+\lambda \cdot \nabla \Delta N_{k, j}+\varepsilon_{k, j}
$$

where $\alpha_{\mathrm{i}}^{\mathrm{k}, \mathrm{j}}=$ difference in the $\alpha_{\mathrm{i}}$ value for stations $\mathrm{k}$ and $\mathrm{j}$.

By forming the double-difference between the inner single-frequency stations, and using the residual vectors from the fiducial reference stations, the inner stations' coordinates can be determined without the need to use any GPS reference station observations. 
At Mt. Papandayan, holding one fiducial site (Bandung) fixed, the baselines to the other two sites are processed and 'correction terms' are obtained for both baselines. These are then weighted according to the position of the inner stations inside the fiducial triangle to generate double-differenced corrections for the inner baselines between the base and slave stations on the volcano.

\section{PROBLEMS ENCOUNTERED DURING FIELD TESTING}

During field testing in February-March 2000 many problems had to be overcome. At the single-frequency GPS sites on the volcano, corrosion due to sulphur gas had severely rusted some of the metal drums containing the equipment during the seven months the equipment had been left on site (Fig. 5). Strong winds destroyed one solar panel even though it was anchored to the ground with concrete. All aluminium and fibreglass components, as well as all surfaces covered with electrical insulation tape, proved resistant to corrosion from the acidic gases. Caustic soda placed inside the drums proved to be an effective method to negate sulphur gas attack on the equipment.

The uninterrupted power supply (UPS) unit and battery charger at the base station of the inner network were modified to guarantee continuous, spike-free power. At the fiducial stations several power outages resulted in data loss due to defect/unreliable battery chargers. As AC power outages are not uncommon in Indonesia, care has to be taken to guard against these conditions, so as to ensure a continuous data set. The PC-based system at the slave stations proved to be unreliable because the amount of available flash PROM (Programmable Read-Only Memory) and RAM (Random Access Memory) decreased over time causing the survey to stop. In future a micro-controller-based system will replace the PCs. One GPS antenna, two antenna cables, one radio and many fuses needed to be replaced.

Initial problems with the baseline software had to be resolved. An error in the decoding of binary CM data into RINEX format was corrected. A lack of broadcast ephemerides was sometimes experienced. In addition, it was difficult to process the single-frequency data collected in the equatorial region during a solar cycle maximum due to an extremely high noise level.

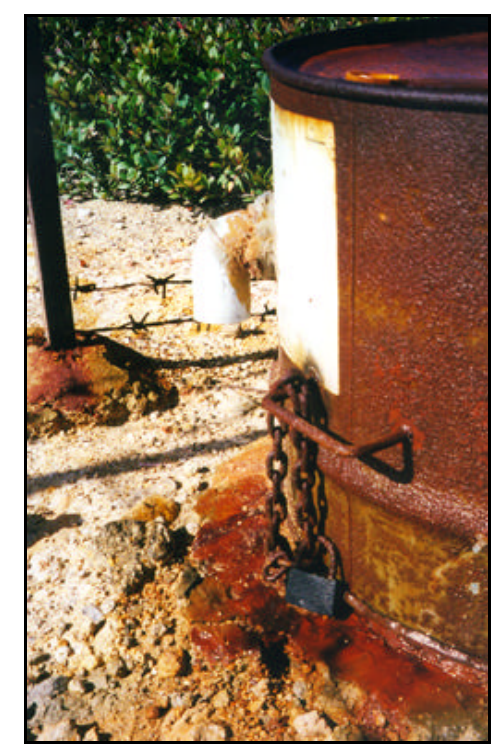

Fig. 5: Heavily corroded metal drum at the GPS slave station Kawah

\section{PRELIMINARY L1-ONLY BASELINES ON MT. PAPANDAYAN}

Time series results of uncorrected data from the inner network are presented below from July 1999 (an earlier campaign) and March 2000. The data was post-processed using the UNSW baseline processing 
software. A double-differencing strategy was used and the standard Saastamoinen model was applied for tropospheric modelling. No antenna phase centre models were applied, as there was no antenna mixing. Given the length of the baselines (maximum about $8 \mathrm{~km}$ ), broadcast ephemerides were considered sufficiently accurate for baseline processing (Rizos, 1997). (In some cases the navigation records of the broadcast ephemerides were not complete and precise ephemerides from the IGS were used. Several baselines were computed using both broadcast and precise ephemerides with no appreciable difference in baseline accuracy, confirming Ibid, 1997.)

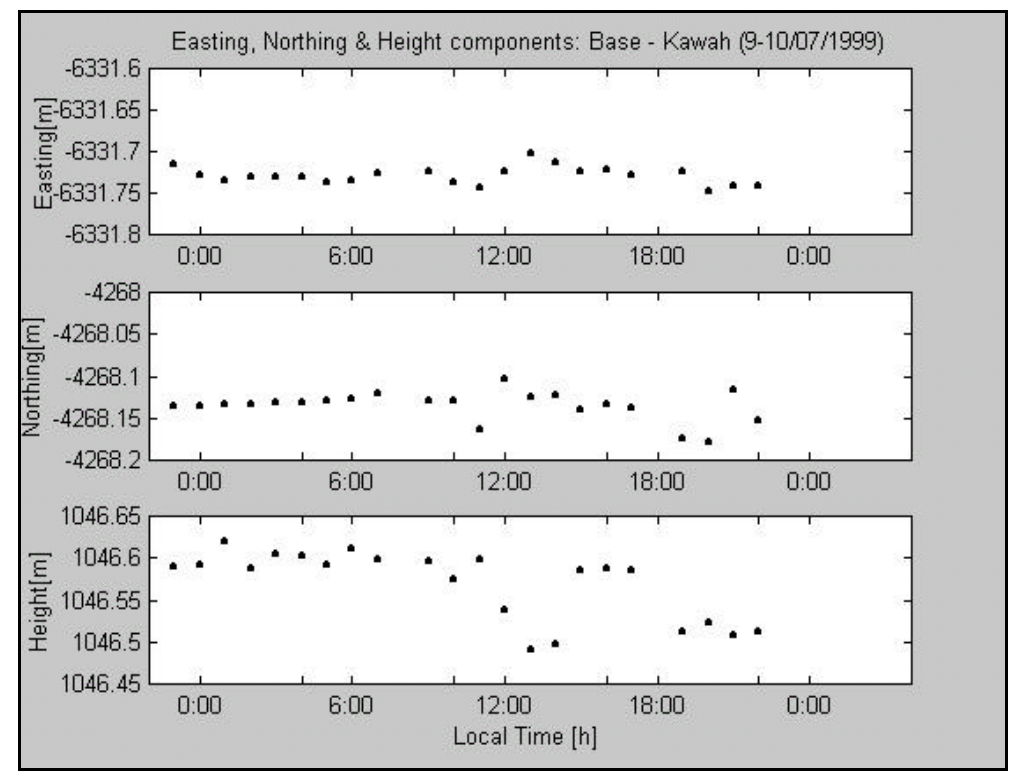

Fig. 6: L1 baseline solutions Base - Kawah (July 1999)

From the data collected in July 1999 (Fig. 6), the easting and northing components indicate a scatter of around $1.4 \mathrm{~cm}$ and $3.7 \mathrm{~cm}$ with corresponding standard deviations of $1.1 \mathrm{~cm}$ and $1.8 \mathrm{~cm}$ respectively. For the height component the scatter is around $6.0 \mathrm{~cm}$ with a standard deviation of $3.9 \mathrm{~cm}$.

Figure 7 shows the baseline results derived from the data collected in March 2000. The easting and northing components show a scatter of around $2.2 \mathrm{~cm}$ and $6.8 \mathrm{~cm}$ with corresponding standard deviations of $1.3 \mathrm{~cm}$ and $3.9 \mathrm{~cm}$ respectively. For the height component the scatter is around $6.5 \mathrm{~cm}$ with a standard deviation of $3.5 \mathrm{~cm}$. These computations assume that there is no movement of the ground surface, and from this small data set certainly no conclusions can (or should) be drawn. Also note that there appear to be more data gaps in the March 2000 data. In fact data was measured during these periods, however, the results were so noisy that it was impossible to derive a meaningful baseline measurement. It is unclear why this is so but given that exactly the same hardware and software was used for both data sets, the authors believe that increased ionospheric activity due to the current solar cycle maximum is the main contributor to this extra noise.

Also note that data gaps appear in a somewhat diurnal manner for the March 2000 data, with data gaps occurring around sunset and continuing until the early hours of the next morning. Seeber (1993) states that ionospheric scintillation effects are most prominent at these times, and particularly around March for Indonesia. This could explain the poor data quality. Additionally, Campos et al (1989) experienced similar problems with the ionosphere during the previous solar cycle maximum. They report relative errors of up to $30 \mathrm{ppm}$ for a $12 \mathrm{~km}$ baseline using L1-only data at a latitude of $8^{\circ}$; conditions very similar to those encountered by the authors. Section 7.3 of this paper discusses the large 'correction terms' obtained when using the proposed ionospheric correction model. The unstable nature of the ionosphere at this time, and hence the high noise level of the GPS data logged, render the automatic baseline processing option for 
single-frequency data not entirely feasible. More research is required to develop an automatic algorithm that handles such signal disturbances.

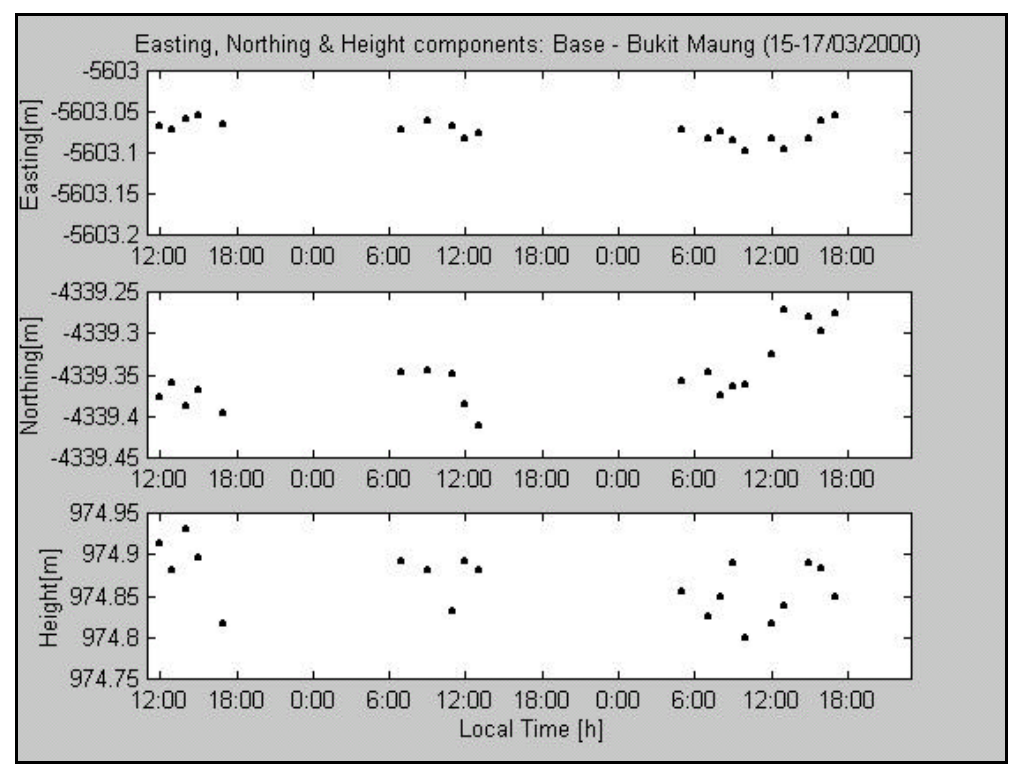

Fig. 7: L1 baseline solutions Base - Bukit Maung (March 2000)

Unfortunately due to the many hardware, software and environmental problems encountered at the time of deployment and observation, a longer and more continuous data set could not be collected. Hence, no comments can be made about actual ground deformation on Mt Papandayan. Many of the hardware faults in the GPS/PC modules can be attributed to the low-performance PC used and its requirement to run under the DOS operating system (an operating system not designed for real-time applications). UNSW is currently investigating changing the hardware of the GPS/PC modules to a micro-controller-based system for increased reliability.

\section{ANALYSIS OF IONOSPHERIC CORRECTIONS}

\subsection{Analysis of field data collected at mid-latitudes}

In order to appreciate what to expect when using the double-differenced 'correction terms', two data sets collected in the mid-latitude region were analysed. Data for different baseline lengths was collected in Japan on 2 January 1997 and 7 March 2000. While the solar activity was rather low in January 1997, it was approaching a maximum during March 2000.

In order to investigate the ionospheric effect on baselines of different lengths, under different solar activity conditions, seven baselines with distances ranging from $26 \mathrm{~km}$ to $101 \mathrm{~km}$ were studied. The GPS stations belong to the Hokkaido network, which is part of Japan's GEONET network, and are equipped with dualfrequency receivers. The data was processed with a modified version of the Bernese software package to generate the empirical corrections. In order to draw conclusions relevant to the volcano application, the following analysis is only concerned with L1 correction terms.

Figure 8 shows the standard deviation of the double-differenced 'correction terms' for different baseline lengths in January 1997 and March 2000. The effect of the increased ionospheric activity due to the solar maximum period in the year 2000 is obvious. It can be seen that the standard deviation increases linearly with increasing baseline length. Under solar sunspot cycle maximum conditions this trend is much more severe. 


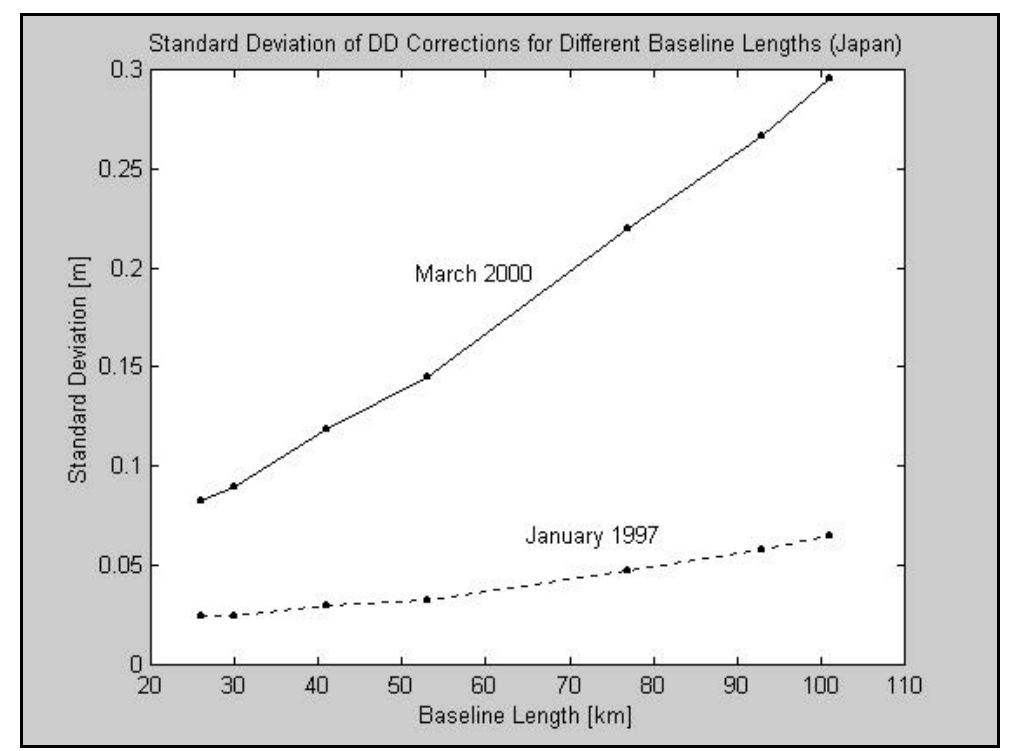

Fig. 8: Standard deviation of double-differenced correction terms for different baseline lengths under low and high solar activity conditions

Figure 9 shows the minimum and maximum correction values obtained for different baseline lengths. It can be seen that the magnitude of the 'correction terms' for longer baselines increases rather rapidly during solar maximum conditions. This suggests that long baselines between reference stations might not be capable of generating reliable corrections under these conditions.

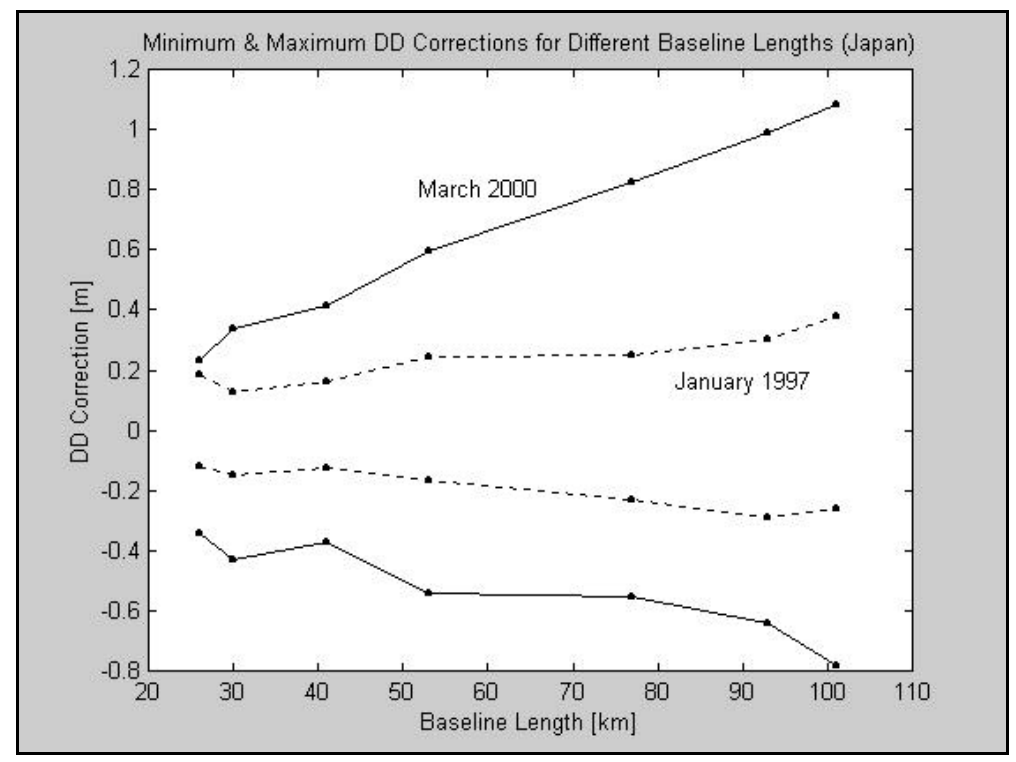

Fig. 9: Minimum and maximum double-differenced correction terms obtained for different baseline lengths

Figure 10 shows the double-differenced corrections for a 77km baseline over 24 hours in January 1997 and then again in March 2000. While the ionosphere remains very calm, and doesn't show much change during the 24-hour observation period in 1997, the effect of the increased ionospheric activity due to the sunspot cycle maximum in the year 2000 is clearly seen. Here, the diurnal variability of the ionosphere in midlatitudes can easily be recognised. As expected, the ionosphere is most active during daylight hours 
between $8 \mathrm{am}$ and 6pm local time, and calms down over night. Between the years 1997 and 2000 the standard deviation increased by a factor of 4.6. The magnitude of the 'correction terms' only ranges from $0.232 \mathrm{~m}$ to $0.248 \mathrm{~m}$ in 1997 , while they vary from $-0.555 \mathrm{~m}$ to $0.824 \mathrm{~m}$ in the year 2000 .

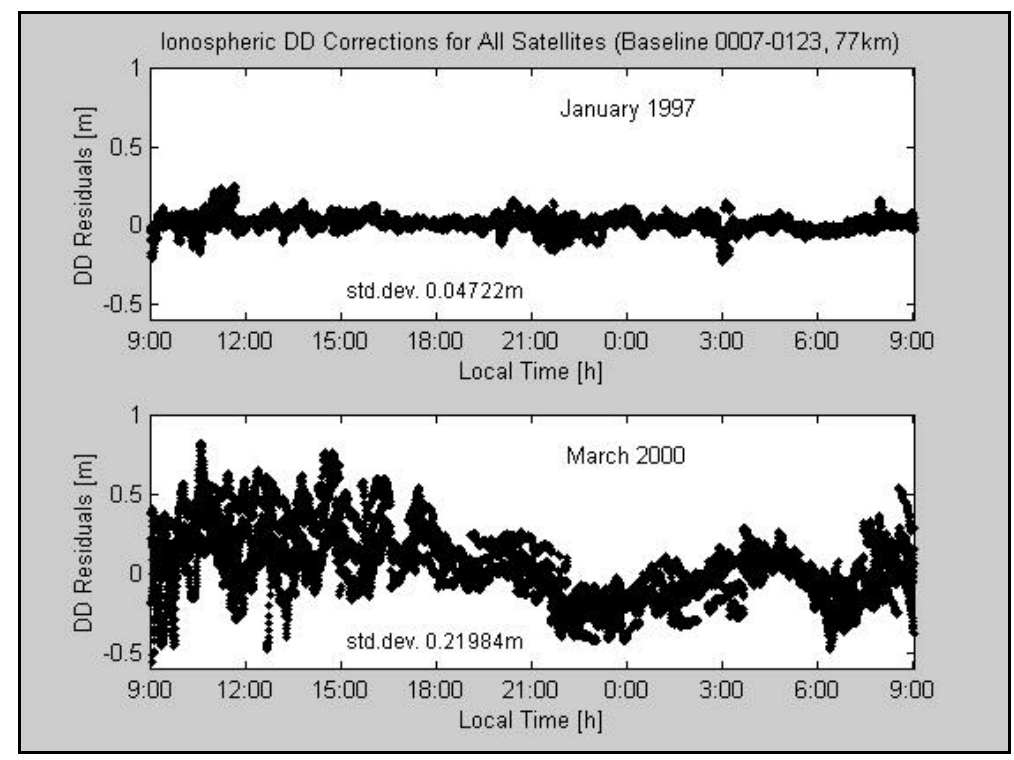

Fig. 10: Double-differenced corrections for a $77 \mathrm{~km}$ baseline over 24 hours under different solar activity conditions

\subsection{Analysis of field data collected in different geographical regions}

The effects of the ionospheric layer on a certain baseline length as a function of geographical location were also investigated. The magnitudes of the double-differenced 'correction terms' for a $30 \mathrm{~km}$ baseline located in mid-latitudes (Japan) and in the equatorial region (Singapore) were compared. The data was collected under sunspot cycle maximum conditions on 7 March 2000, and the results are shown in Figure 11. The more severe ionospheric delay effects in the equatorial region are obvious. In Singapore the magnitude of the minimum and maximum corrections are $-0.610 \mathrm{~m}$ and $0.681 \mathrm{~m}$ respectively, (with a standard deviation of $0.170 \mathrm{~m}$ ), while in Japan the values only range from $-0.146 \mathrm{~m}$ to $0.126 \mathrm{~m}$ (with a standard deviation of $0.089 \mathrm{~m}$ ). The standard deviation has doubled while the maximum/minimum values have increased by a factor of 4. In addition, it can be seen that the ionospheric effect is mainly a daytime phenomenon in midlatitudes. However, the graph shows that there is also a lot of ionospheric activity between local noon and sunset in Singapore. This is contrary to the expectation that most of the ionospheric activity occurs between sunset and midnight in equatorial regions. This might be due to intensified small-scale disturbances in the ionosphere during a period of increased solar activity. 


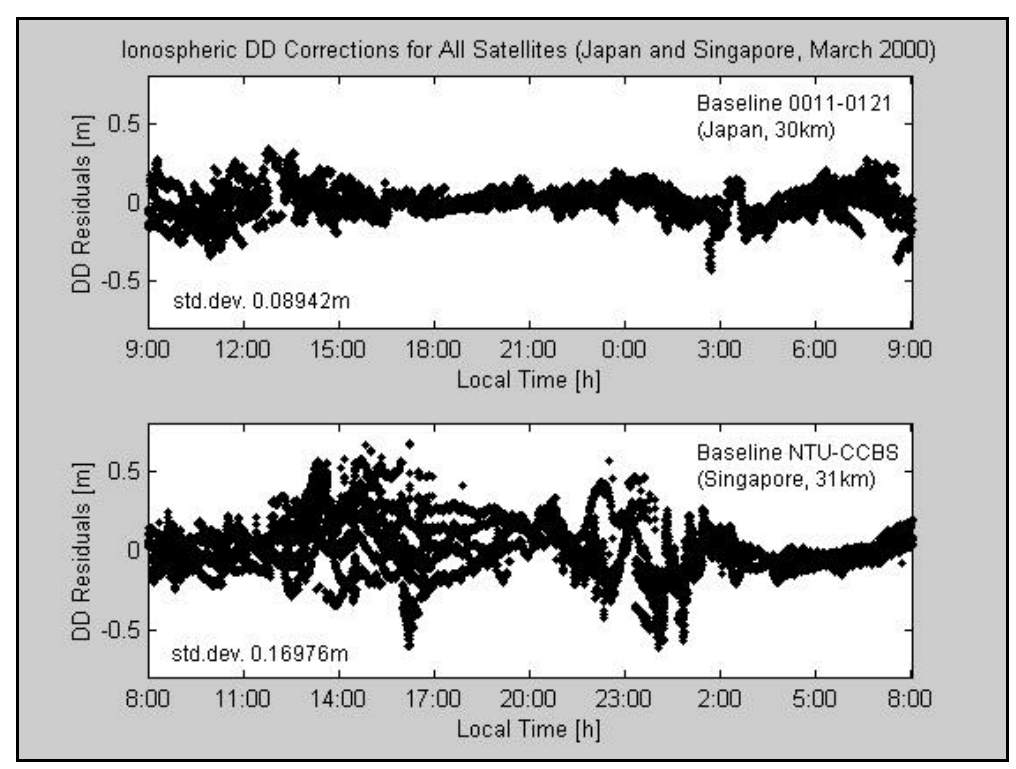

Fig. 11: Double-differenced corrections for a 30km baseline over 24 hours in different geographical regions (mid-latitude region and equatorial region)

\subsection{Analysis of field data collected at the Mt. Papandayan volcano}

The ionospheric activity at the Mt. Papandayan volcano is expected to be higher than experienced in Japan. While the Japanese test network is located in the mid-latitude region, Mt. Papandayan is very close to the magnetic equator. Here, the most severe ionospheric effects are scintillations, which are generally present between approximately one hour after local sunset to midnight. Figure 12 shows the double-differenced 'correction terms' generated by the three fiducial baselines BAND-PAME (85km), BAND-GALU (72km) and GALU-PAME $(60 \mathrm{~km})$ over 24 hours on 7 March 2000. It can be seen that the 'correction terms' for the two baselines BAND-PAME and BAND-GALU, which are supposed to generate the corrections to be used in the data processing, are very large. In fact, they appear to be too large to be representative of the network area. The magnitude of the 'correction terms' range from $-5.556 \mathrm{~m}$ to $4.597 \mathrm{~m}$ (BAND-PAME) and from $-2.976 \mathrm{~m}$ to $2.830 \mathrm{~m}$ (BAND-GALU), with standard deviations of $1.025 \mathrm{~m}$ and $0.719 \mathrm{~m}$ respectively. The 'correction terms' for the third baseline range from $-1.563 \mathrm{~m}$ to $1.504 \mathrm{~m}$ with a standard deviation of $0.377 \mathrm{~m}$, giving slightly more realistic values. This suggests that baselines longer than approximately $60 \mathrm{~km}$ will not be able to generate reliable 'correction terms' under solar maximum conditions. It can be seen that the maximum ionospheric effects are present between local sunset and midnight, which is as expected. However, there is also a lot of activity between $3 \mathrm{pm}$ and sunset. As mentioned before, this could be explained by intensified disturbances in the ionosphere caused by the increased sunspot cycle activity. Due to the high magnitude of the 'correction terms' and the lack of a more continuous data set, the authors refrained from applying the corrections to the single-frequency data. 


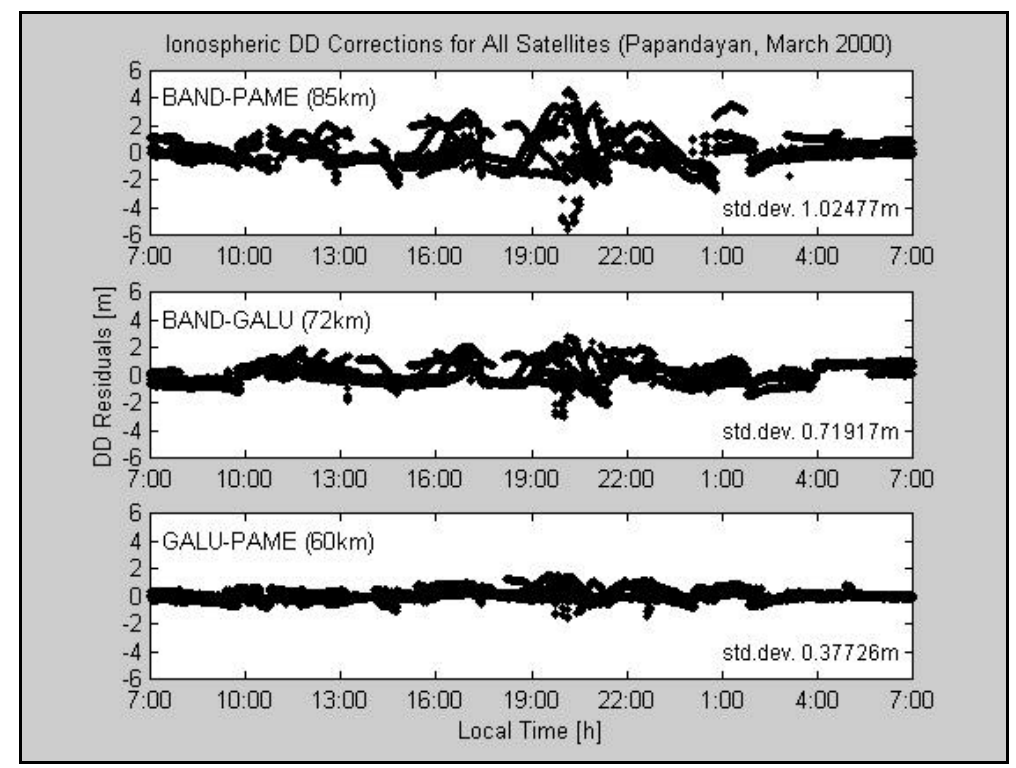

Fig. 12: Double-differenced corrections for the fiducial baselines at Mt. Papandayan, Indonesia over 24 hours in March 2000

\section{CONCLUDING REMARKS}

The design of a low-cost mixed-mode GPS volcano monitoring system on Mt. Papandayan in West Java, Indonesia has been described. Field testing revealed severe effects of the ionosphere on single-frequency baseline repeatability, and on the 'correction terms' generated by dual-frequency GPS receivers intended to mitigate the ionospheric effects.

The variability of the single-frequency baselines measured in July 1999 and March 2000 has highlighted the extreme nature of ionospheric disturbances in equatorial regions during a sunspot cycle maximum. The data quality from July 1999 was clearly better than from March 2000. Given the short length of the baselines, no ionospheric modelling was used for the post-processing of the L1 data, however, the extreme data noise in March 2000 precluded the processing of some baselines. These data gaps appear to display a diurnal pattern, which could be explained by an anticipated higher probability of phase scintillations, or simply due to a higher Total Electron Content value, compared to the July 1999 data. The unusually large ionospheric corrections determined using the correction generation algorithm proposed by the authors lends weight to the claim that the ionosphere is the cause of this noise. Automatic single-frequency processing of baselines is consequently not yet feasible.

A range of data sets were processed in order to investigate the nature of the empirically derived doubledifferenced 'correction terms'. The GPS data analysed included a variety of baseline lengths, in different geographical locations and at different periods of sunspot activity (and hence ionospheric conditions). The following conclusions can be drawn:

- The standard deviation of the double-differenced 'correction terms' increases linearly with increasing baseline length.

- A large increase in solar activity is evident between the 1997 and 2000 data sets.

- During solar sunspot cycle maximum conditions the magnitude of the 'correction terms' for longer baselines in the mid-latitudes reaches a few cycles. This indicates that long dual-frequency baselines may not be able to generate reliable corrections under these conditions.

- Increased ionospheric activity during the daytime in mid-latitudes and after sunset in the equatorial region is evident. As expected, the ionospheric effects for sites at the equator are much larger compared to mid-latitude sites. 
- The distances between the fiducial stations around the Mt. Papandayan volcano should be reduced to approximately $50-60 \mathrm{~km}$ to generate reliable corrections during solar sunspot cycle maximum conditions as are being experienced in 2000-2001.

If the locations of the fiducial sites are appropriately chosen, it is possible to use one fiducial network to generate corrections for a number of different volcanoes within the network. Hence, the cost of this mixedmode volcano deformation monitoring system can be further reduced. However, if the spacing of the fiducial stations is too large, reliable corrections cannot be obtained.

Future generations of this volcano monitoring system will utilise a micro controller-based system, which is better suited to real-time applications. The authors believe that with an appropriately designed fiducial network surrounding the inner single-frequency network the ionospheric 'correction terms' can indeed enhance baseline accuracy even during times of high ionospheric activity. Additionally the second author is investigating the effects of differential troposphere on height repeatability in equatorial regions.

\section{ACKNOWLEDGEMENTS}

This project is a joint venture between The University of New South Wales (UNSW), Sydney, Australia, the Institute of Technology Bandung and the Vulcanological Survey of Indonesia (both in Bandung, Indonesia). Without the valuable help of all partners this project would not have been possible. The Australian Research Council (ARC) is funding the development and deployment of the GPS-based volcano monitoring system in Indonesia. The staff of the National Aeronautics and Space Agency (LAPAN) observatory in Pameungpeuk, Indonesia, are thanked for hosting one of the fiducial network stations. The GEONET (GPS Earth Observation Network) data was made available by the Geographical Survey Institute of Japan. The first author is supported by an International Postgraduate Research Scholarship and funding from the ARC. The second author is also supported by funding from the ARC.

\section{REFERENCES}

Abidin, H.Z., I. Meilano, O.K. Suganda, M.A. Kusuma, D. Muhardi, O. Yolanda, B. Setyadji, R. Sukhyar, J. Kahar \& T. Tanaka 1998. Monitoring the deformation of Guntur Volcano using repeated GPS survey method. FIG '98, XXI Int. Conf., Brighton, UK, 19-25 July.

Berntsen International Inc. 2001. http://www.berntsen.com.

Briole, P., D. Massonnet \& C. Delacourt 1997. Post-eruptive deformation associated with the 1986-87 and 1989 lava flows of Etna detected by radar interferometry, Geophysical Research Letters, 24(1), 37-40.

Campos, M.A., G. Seeber \& G. Wübbena 1989. Positioning with GPS in Brazil, Proc. $5^{\text {th }}$ Int. Geod. Symp. on Satellite Positioning, Vol. 1, Las Cruces, New Mexico, 13-17 March, 526-535.

Chen, H.Y., C. Rizos \& S. Han 1999. Rapid static, medium-range GPS positioning techniques for geodynamic applications, $4^{\text {th }}$ Australasian Symp. on Satellite Navigation Technology \& Applications, Brisbane, Australia, 20-23 July, Paper 49, 12pp.

Han, S. 1997. Carrier phase-based long-range GPS kinematic positioning, PhD Dissertation, UNISURV S49, School of Geomatic Engineering, The University of New South Wale s, Sydney, Australia, 185pp.

Han, S., \& C. Rizos 1996. GPS network design and error mitigation for real-time continuous array monitoring systems, Proc. 9th Int. Tech. Meeting of the Satellite Division of the U.S. Inst. of Navigation, Kansas City, Missouri, 17-20 September, 1827-1836.

IPS Radio \& Space Services 2000. Space weather and satellite communications, Sydney, Australia, http://www.ips.gov.au/papers/richard/space_weather_satellite_communications.html, 7pp. 
Klobuchar, J.A. 1996. Ionospheric effects on GPS, in: Parkinson, B.W. \& J.J. Spilker (Eds.) 1996: Global Positioning System: Theory and Applications Volume I, Progress in Astronautics and Aeronautics, 163, American Institute of Aeronautics and Astronautics, Washington, 485-515.

Lu, Z., R. Fatland, M. Wyss, S. Li, J. Eichelberger, K. Dean \& J. Freymueller 1997. Deformation of New Trident volcano measured by ERS-1 SAR interferometry, Katmai National Park, Alaska, Geophysical Research Letters, 24(6), 695-698.

Meertens, C. 1999. Development of as L1-phase GPS volcano monitoring system-Progress report for the period 12 August 1998 - 15 May 1999, http://www.unavco.ucar.edu/science_tech/volcano/11.

Nishi, K., H. Ono \& H. Mori 1999. Global Positioning System measurements of ground deformation caused by magma intrusion and lava discharge: the 1990-1996 eruption at Unzendake volcano, Kyushu, Japan. J. Volcanol. Geotherm. Res., 89, pp 23-34.

Nunnari, G. \& G. Puglisi 1994. The Global Positioning System as a useful technique for measuring ground deformation in volcanic areas. J. Volcanol. Geotherm. Res., 61, pp 267 - 280.

Omori, F. 1914. The Sakur-jima eruptions and earthquakes. Bulletin of the Imperial Earthquake Investigation Committee 8, Nos 1-6, 525.

Rizos, C. 1997. Principles and Practice of GPS Surveying, Monograph 17, School of Geomatic Engineering, The University of New South Wales, Sydney, Australia, 555pp.

Rizos, C., S. Han \& H.Y. Chen 1998. Carrier phase-based, medium-range, GPS rapid static positioning in support of geodetic applications: Algorithms and experimental results, Proc. Spatial Information Science \& Technology (SIST'98), Wuhan Technical University of Surveying and Mapping, Wuhan, P.R. China, 1316 September, 7-16.

Rizos, C., S. Han, L. Ge, H.Y. Chen, Y. Hatanaka \& K. Abe 1999. Low-cost densification of permanent GPS networks for natural hazard mitigation: First tests on GSI's GEONET network, Earth, Planets and Space (EPS), special volume on proc. of the Int. Symp. on GPS - Applications to Earth Sciences \& Interaction with other Space Geodetic Techniques, Tsukuba, Japan, 18-22 October, 6pp.

Rizos, C., S. Han, C. Roberts, X. Han, H.Z. Abidin, O.K. Suganda \& A.D. Wirakusumah 2000. Continuously operating GPS-based volcano deformation monitoring in Indonesia: The technical and logistical challenges, in: Schwarz, K.-P. (Ed.) 2000. Geodesy Beyond 2000: The Challenges of the First Decade, Proc. IAG General Assembly, Birmingham, UK, 19-30 July 1999, Springer, 361-366.

Seeber, G. 1993. Satellite Geodesy, de Gruyter, Berlin, Germany, 531pp.

Shimada, S., Y. Fujinawa, S. Sekiguchi, S. Ohmi, T. Eguchi \& Y. Okada 1990. Detection of a volcanic fracture opening in Japan using Global Positioning System measurements. Nature, Vol. 343, 15 February, 631-633.

Suganda, O.K. 1993. Analysis of EDM data in association with the 1992 eruption at Merapi Volcano, Indonesia. Masters Thesis, Department of Geophysics, Kyoto University, Japan.

Wanninger, L. 1999. The performance of virtual reference stations in active geodetic GPS-networks under solar maximum conditions, Proc. 12th Int. Tech. Meeting of the Satellite Division of the U.S. Inst. of Navigation, Nashville, Tennessee, 14-17 September, 1419-1427.

Wu, J.T. 1994. Weighted differential GPS method for reducing ephemeris error, Manuscripta Geodaetica, 20, 1-7. 